\title{
Regulation of TRPM8 channel activity by Src-mediated tyrosine phosphorylation
}

\author{
Alexandra Manolache $^{1}$ | Tudor Selescu ${ }^{1}$ | G. Larisa Maier ${ }^{1}$ Mihaela Mentel ${ }^{2}$ | \\ Aura Elena lonescu $^{2}$ | Cristian Neacsu ${ }^{1}$ | Alexandru Babes ${ }^{1}$ (] \\ Stefan Eugen Szedlacsek ${ }^{2}$ (1)
}

${ }^{1}$ Department of Anatomy, Physiology and Biophysics, Faculty of Biology, University of Bucharest, Bucuresti, Romania

${ }^{2}$ Department of Enzymology, Institute of Biochemistry of the Romanian Academy, Bucuresti, Romania

\section{Correspondence}

Alexandru Babes and Stefan Eugen Szedlacsek, Department of Enzymology, Institute of Biochemistry, Spl Independentei, 296 Bucuresti 060031, Romania.

Email: alexandrubabes@hotmail.com (A. B.) and stefan.szedlacsek@biochim.ro (S. E. S.)

Present address

G. Larisa Maier, Department of Biology, Institute of Zoology, University of Fribourg, Fribourg, Switzerland

Mihaela Mentel, Regional Institute of Oncology, TRANSCEND Center, Iasi, Romania

Cristian Neacsu, Department of Life and Environmental Sciences, Horia Hulubei National Institute for Research and Development in Physics and Nuclear Engineering (IFIN-HH), Măgurele, Romania.

\section{1 | INTRODUCTION}

Mammals possess 28 subtypes of transient receptor potential (TRP) channels, eight of which belong to the melastatin subgroup (TRPM) and are responsible for a variety of cellular functions (Mickle, Shepherd, \& Mohapatra, 2015). TRPM8 is a temperature-gated ion channel found in the peripheral nervous system (PNS), but also in non-neuronal tissue, such as the prostate (Babes, Ciobanu, Neacsu, \& Babes, 2011). It is activated by a decrease in ambient temperature, natural compounds

\begin{abstract}
The transient receptor potential melastatin type 8 (TRPM8) receptor channel is expressed in primary afferent neurons where it is the main transducer of innocuous cold temperatures and also in a variety of tumors, where it is involved in progression and metastasis. Modulation of this channel by intracellular signaling pathways has therefore important clinical implications. We investigated the modulation of recombinant and natively expressed TRPM8 by the Src kinase, which is known to be involved in cancer pathophysiology and inflammation. Human TRPM8 expressed in HEK293T cells is constitutively tyrosine phosphorylated by Src which is expressed either heterologously or endogenously. Src action on TRPM8 potentiates its activity, as treatment with PP2, a selective Src kinase inhibitor, reduces both TRPM8 tyrosine phosphorylation and cold-induced channel activation. RNA interference directed against the Src kinase diminished the extent of PP2-induced functional downregulation of TRPM8, confirming that PP2 acts mainly through Src inhibition. Finally, the effect of PP2 on TRPM8 cold activation was reproduced in cultured rat dorsal root ganglion neurons, and this action was antagonized by the protein tyrosine phosphatase inhibitor pervanadate, confirming that TRPM8 activity is sensitive to the cellular balance between tyrosine kinases and phosphatases. This positive modulation of TRPM8 by Src kinase may be relevant for inflammatory pain and cancer signaling.

KEYWORDS

channel activity, cultured rat dorsal root ganglion neurons, Src-mediated tyrosine phosphorylation, TRPM8
\end{abstract}

(menthol, eucalyptol, camphor) or synthetic ligands (icilin, WS12; Bödding Wissenbach, \& Flockerzi, 2007) and modulated by changes in membrane potential (Fernández et al., 2011). One of the main physiological functions of TRPM8 is to detect innocuous cold, and genetic deletion of this channel interferes with normal temperature preference behavior (Bautista et al., 2007). Inflammation and nerve injury are associated with enhanced cold sensitivity, and TRPM8 contributes to these alterations in temperature sensing (Knowlton, Bifolck-Fisher, Bautista, \& McKemy, 2010; Dhaka et al., 2007). 
TRPM8 is expressed in a variety of cancer types including breast, prostate, lung, and colon, but it is also expressed in nonmalignant tissues (Hantute-Ghesquier, Haustrate, Prevarskaya, \& Lehen'kyi, 2018; Yudin \& Rohacs, 2012). At subcellular level, TRPM8 is expressed both in the endoplasmic reticulum and plasma membrane of LNCaP prostate cancer epithelial cells (Noyer, Grolez, Prevarskaya, Gkika, \& Lemonnier, 2018). Plasma membrane localization has been linked to a higher apoptosis rate and cancer progression was associated with channel internalization through ubiquitination (Asuthkar, Demirkhanyan, Mueting, Cohen, \& Zakharian, 2017; Asuthkar, Velpula, Elustondo, Demirkhanyan, \& Zakharian, 2015). The initial article on TRPM8 reported its upregulation in prostate cancer and in primary tumors of breast, colon, lung and skin origin (Tsavaler, Shapero, Morkowski, \& Laus, 2001). However, according to later reports, its role can be either stimulatory in cell proliferation of prostate, breast or pancreatic cells or inhibitory in migration of prostate cancer cells or in the proliferation of melanoma cells (Cucu et al., 2014; Hantute-Ghesquier et al., 2018).

Apart from its role in cold sensing, TRPM8 plays an essential role both in physiological and in pathological processes like endothelial cell motility, extracellular matrix degradation, proliferation, oxidative stress or protein unfolding (Noyer et al., 2018). Thus, it is expected to be under strict control of regulatory mechanisms. Indeed, it has been shown that the channel activity of the purified protein requires the presence of phosphoinositides and inorganic polyphosphate (Zakharian, Thyagarajan, French, Pavlov, \& Rohacs, 2009). Testosterone also associates with TRPM8, acting as a potent agonist of the channel (Asuthkar et al., 2015). Activity of TRPM8 is also regulated by two short splice variants of the channel, sM8 $\alpha$ and sM8 $\beta$, which generate proteins sM8-6 and sM8-18. The sM8-6 isoform downregulates TRPM8 activity by interacting with the C-terminus of the receptor and inducing through allosteric modulation the closed state of the channel (Fernández et al., 2012).

It has been evidenced since long that protein phosphorylation may significantly contribute to the modulation of ion channels' activity. Thus, Ser/Thr protein kinases such as PKC, PKA, or Tyr kinases like Src-kinase can regulate the activity of numerous thermo-TRPs. For example, a number of Ser and Thr residues on TRPV1 were identified as phosphorylation targets of protein kinases, though only some of them were found as modulators of the temperature-sensitive ion current (Huang, Zhang, \& McNaughton, 2006). Ser/Thr phosphorylation of TRPM8 has also been reported. Thus, it has been shown that activation of PKC by phorbol esters leads to reduced serinephosphorylation and functional downregulation of TRPM8. These effects are attributable to PKC-mediated activation of Ser/Thr phosphatases like PP2A (Premkumar et al., 2005). The regulatory effect of tyrosine phosphorylation on the TRPV subfamily has been intensively studied. Thus, it was shown that Src-mediated phosphorylation of TRPV1 at Tyr200 leads to modulation of subcellular trafficking of TRPV1 to the plasma membrane (X. Zhang, Huang, \& McNaughton, 2005). On the other hand protein tyrosine phosphatase (PTP) Shp-1 dephosporylates TRPV1 in dorsal root ganglion (DRG) neurons and reduces the inflammatory pain in rats, induced by Complete Freund's adjuvant (Xiao et al., 2015). Similarly, TRPV4 phosphorylation by Src family kinases, in different cell lines has been reported. Two novel phosphorylation sites in the cytosolic $\mathrm{N}$ - and $\mathrm{C}$ terminal tails of TRPV4 were identified. The $\mathrm{N}$-terminal tyrosine plays a crucial role in the activation of TRPV4 by heat, mechanical stress, hypotonic cell swelling, and phorbol 12-myristate 13-acetate (Wegierski, Lewandrowski, Müller, Sickmann, \& Walz, 2009).

The number of reports on the modulatory role of tyrosine phosphorylation on members of the TRPM subclass is limited. TRPM2 tyrosine phosphorylation was demonstrated and it was found that tyrosine phosphorylation is important in TRPM2 activation and function (W. Zhang et al., 2007). As concerning TRPM8, it was shown that PP2 (a selective Src family tyrosine kinase inhibitor) inhibited, in a dose-dependent manner, the agonist-induced responses of TRPM8 expressed in SH-SY5Y cells (Morgan, Sadofsky, Crow, \& Morice, 2014). However, it is still unclear which tyrosine kinase mediates phosphorylation and how phosphorylation modulates cold-induced responses in cell lines expressing TRPM8, as well as in cultured neurons. We report here that TRPM8 is tyrosine phosphorylated by Src and partly by TrkA kinases. Our results show that pervanadate $(\mathrm{PV})$ treatment stimulates while PP2 treatment prevents phosphorylation of TRPM8 in cells expressing TRPM8. We also provide evidence that inhibition of endogenous Src kinase diminishes both phosphorylation and cold-induced activation of TRPM8. In cultured rat DRG neurons PP2 and dasatinib (another Src kinase inhibitor) were found to downregulate TRPM8-mediated responses, effect which was antagonized by PV.

\section{2 | MATERIALS AND METHODS}

\section{1 | Cell culture and transfection procedures}

Human embryonic kidney 293T (HEK293T) cells were cultured in Dulbecco's modified Eagle's medium (DMEM), supplemented with $10 \%$ fetal bovine serum, $1 \times$ non-essential amino acids and $1 \times$ sodium pyruvate (all from Thermo Fisher Scientific). For biochemical experiments, we used human TRPM8 (UniProt Q7Z2W7) with an $\mathrm{N}$-terminus VSV-G tag (sequence YTDIEMNRLGK; VSV-G-TRPM8). cDNAs coding for VSV-G-TRPM8, a constitutively active form of Src (SrcY527F), Abl, Btk, and TrkA protein tyrosine kinases were introduced into HEK293T cells by polyethylenimine (PEI; Sigma) transfection (DNA:PEI 1:3). Cells were transfected at $60-70 \%$ confluency with $8 \mu \mathrm{g}$ of VSV-G-TRPM 8 DNA $/ 25 \mathrm{~cm}^{2}$ flask. In VSVG-TRPM8/tyrosine kinase co-expression experiments cells were transfected with a total of $8 \mu \mathrm{g}$ of DNA $/ 25 \mathrm{~cm}^{2}$ flask ( $6 \mu \mathrm{g}$ of VSVG-TRPM8 DNA and $2 \mu \mathrm{g}$ DNA for tyrosine kinases). Cells were harvested after $48 \mathrm{hr}$ of transfection. For calcium microfluorimetry recordings we used HEK293 cells stably expressing human TRPM8 (HEK293-hTRPM8 cells) maintained in DMEM F12 medium supplemented with $10 \%$ fetal bovine serum, $1 \%$ penicillin/streptomycin, $1 \%$

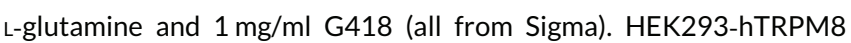
cells were transfected at $60-70 \%$ confluency with $0.6 \mu \mathrm{g}$ of SrcY527F DNA/35 mm dish using Jet-PEI (Polyplus; DNA:Jet-PEI 1:2.5). Calcium microfluorimetry recordings were performed $48 \mathrm{hr}$ after 
transfection. For Src kinase silencing, HEK293-hTRPM8 cells were transfected with Silencer ${ }^{\circledR}$ Select Pre-Designed \& Validated siRNA (Ambion/Thermo Fisher Scientific) and Silencer ${ }^{\circledR}$ Select Negative Control \#1 siRNA (scrambled RNA; the producer company refuse to disclose the sequence of the Silencer Select negative control) was used as control. siRNA was generated against the human Src sequence 5'-GCCTCTCAGTGTCTGACTT-3'. Cells were transfected at $30-40 \%$ confluency with $10 \mathrm{nM}$ siRNA or Scrambled RNA, using Lipofectamine RNAiMax (Invitrogen). After $96 \mathrm{hr}$, cells were either used for calcium microfluorimetry recordings or were harvested for biochemical experiments.

\section{2 | Cell treatment}

For biochemical experiments, cells transfected with VSV-G-TRPM8 were treated with $1 \mathrm{mM} \mathrm{PV}$, a protein tyrosine phosphatase inhibitor. Cells were incubated with PV in complete DMEM medium for $15 \mathrm{~min}$ and then harvested. HEK293T cells cotransfected with VSV-GTRPM8 and SrcY527F were incubated with $10 \mu \mathrm{M}$ PP2 (Sigma) in complete DMEM medium for the indicated times.

\subsection{Cell lysis and BCA assay}

All cells were washed with ice-cold phosphate-buffered saline and then harvested in ice-cold $50 \mathrm{mM}$ Tris Base $\mathrm{pH} 7.4,150 \mathrm{mM} \mathrm{NaCl}$, $10 \mathrm{mM} \mathrm{MgCl}_{2}, 10 \%$ glycerol and 1\% Nonidet-P40 (1\% Nonidet-P40 lysis buffer) supplemented with $1 \mathrm{X}$ protease inhibitor cocktail (Santa Cruz Biotechnology Inc), $1 \mathrm{mM}$ phenylmethylsulfonyl fluoride, $1 \mathrm{mM}$ orthovanadate and $5 \mathrm{mM}$ iodacetic acid. The cells were passed through a needle 10 times then kept on ice for $20 \mathrm{~min}$. Cell lysates were clarified by centrifugation $\left(20,000 \mathrm{~g}, 30 \mathrm{~min}, 4^{\circ} \mathrm{C}\right)$. To determine total protein concentration, we used the BCA assay (Bicinchoninic acid assay; Thermo Fisher Scientific). Briefly, a volume of $10 \mu$ of cell lysate was incubated with $200 \mu \mathrm{l}$ working reagent (reagentA:reagentB 50:1) for $30 \mathrm{~min}$ at $37^{\circ} \mathrm{C}$ and then the sample absorbances were read at $480 \mathrm{~nm}$. Lysate samples were diluted in $2.5 \times$ sodium dodecyl sulfate (SDS)-gel loading buffer, boiled for $5 \mathrm{~min}$ at $70^{\circ} \mathrm{C}$ and then used for western blot assay to verify protein expression.

\section{4 | Immunoprecipitation}

VSV-G-TRPM8 was immunoprecipitated from the lysate supernatant using a mouse monoclonal VSV-G antibody (Santa Cruz Biotechnology Inc.; sc365019). Lysate supernatants were incubated for $1 \mathrm{hr}$ at $4^{\circ} \mathrm{C}$ with the VSV-G antibody followed by overnight incubation with protein G-Sepharose beads (Sigma). Protein G-Sepharose beads were washed and equilibrated in $1 \%$ nonidet-P40 lysis buffer. The immunoprecipitates were washed three times with ice-cold lysis buffer, diluted in $1 \times$ SDS-gel loading buffer, boiled for $5 \mathrm{~min}$ at $70^{\circ} \mathrm{C}$ and used for western blot assay to verify VSV-G-TRPM8 tyrosine phosphorylation.

\section{5 | Western blot analysis}

Proteins from cell lysates were separated by SDS-polyacrylamide gel electrophoresis on a $10 \%$ polyacrylamide gel and immunoprecipitated samples were separated on a $7.5 \%$ polyacrylamide gel. Proteins were transferred to polyvinylidene fluoride membranes and the blots were blocked for $40 \mathrm{~min}$ in $5 \%$ milk (Sigma) or 10\% BSA (Santa Cruz Biotechnology Inc) diluted in Tris-buffered saline with $0.1 \%$ Tween-20 (TBS-T) $1 \times$ and incubated with primary antibodies for $1 \mathrm{hr}$ at room temperature. The blots were washed three times at $10 \mathrm{~min}$ interval in TBS-T $1 \times$ and were incubated with the secondary antibodies for $1 \mathrm{hr}$ at room temperature. Western blot analysis Luminol Reagent (Santa Cruz Biotechnology Inc) was used to detect the proteins of interest by exposure on an X-ray film.

\section{6 | Antibodies and reagents}

VSV-G-TRPM8 expression was detected with the mouse monoclonal VSV-G antibody used for immunoprecipitation. Src expression (SrcY527F and c-src) was detected with a mouse monoclonal Src antibody (Millipore; MABS193, clone327) and the phosphorylation of tyrosine 418 was detected by the rabbit polyclonal Src (phospho418) antibody (Abcam; ab4816). Abl and Btk tyrosine kinases had a flag tag (DYKDDDDK sequence) and were detected using a mouse monoclonal flag M2 antibody (Sigma; F1804). TrkA tyrosine kinase was detected using a rabbit polyclonal TrkA antibody (Alomone Labs; ANT-018). Actin was detected by a mouse monoclonal actin antibody (BD Bioscience; cat \#612657). Tyrosine-phosphorylated VSV-G-TRPM8 was detected by the mouse monoclonal antibody pTyr(pY99)-HRP (Santa Cruz Biotechnology Inc; sc-7020) that recognizes phosphotyrosine.

\section{7 | Rat DRG culture}

Adult male Wistar rats $(150-200 \mathrm{~g} ; n=9)$ from the Institute of Cellular Biology and Pathology "Nicolae Simionescu", Bucharest, Romania were used. Animal handling procedures were performed in accordance with the EU Directive 2010/63/EU revising Directive 86/ $609 / E E C$ concerning the protection of animals used for research purposes and were approved by the Bioethics Committee of the Faculty of Biology, University of Bucharest. The rats were euthanized by inhalation of $100 \% \mathrm{CO}_{2}$ for $2 \mathrm{~min}$ and then decapitated. DRGs from T12-S1 spinal segments were dissected out and placed in $2 \mathrm{mg} /$ $\mathrm{ml}$ collagenase (from Clostridium histolyticum, type $\mathrm{XI}$; Sigma) and $3 \mathrm{mg} / \mathrm{ml}$ dispase (Gibco) for $1 \mathrm{hr}$ at $37^{\circ} \mathrm{C}$ in IncMix solution ( $155 \mathrm{mM}$ $\mathrm{NaCl}, 1.5 \mathrm{mM} \mathrm{K}_{2} \mathrm{HPO}_{4}, 5.6 \mathrm{mM}$ 4-(2-hydroxyethyl)-1-piperazineethanesulfonic acid [HEPES], $4.8 \mathrm{mM}$ Na-HEPES, $5 \mathrm{mM}$ glucose, adjusted to $\mathrm{pH} 7.4$ with $\mathrm{NaOH}$ ). Following incubation, DRG neurons were mechanically dissociated, plated on $25-\mathrm{mm}$ glass coverslips which had been coated with poly-D-lysine $(0.1 \mathrm{mg} / \mathrm{ml}$; Sigma) for $30 \mathrm{~min}$ and cultured in DMEM F12 medium supplemented with $10 \%$ horse serum (Sigma) and gentamicin (50 $\mathrm{\mu g} / \mathrm{ml}$; Sigma) at $37^{\circ} \mathrm{C}$ and $5 \% \mathrm{CO}_{2}$. 


\section{8 | Intracellular nonratiometric calcium microfluorimetry (used with HEK293 cells and rat DRG neurons)}

HEK293-hTRPM8 cells and DRG neurons cultured on $25 \mathrm{~mm}$ glass coverslips were maintained in standard ECS (see Section 2.9) containing $2 \mu \mathrm{M}$ Calcium Green-1 AM and 0.02\% Pluronic F-127 (both from Invitrogen) for $30 \mathrm{~min}$ at $37^{\circ} \mathrm{C}$ and allowed $30 \mathrm{~min}$ to recover before use. Coverslips were mounted in a Teflon chamber (MSC TD, Digitimer, Welwyn Garden, UK) on the stage of an Olympus IX70 inverted microscope. Temperature stimuli were applied through local superfusion using a Peltier-based system (Reid, Amuzescu, Zech, \& Flonta, 2001). We also used a miniature thermocouple (1T-1E, Physitemp, Clifton, NJ) placed very close to the cells to measure in real time the temperature experienced by the imaged cells during the experiment. For HEK293hTRPM8 cells, cold ramps (from $\sim 32^{\circ} \mathrm{C}$ to $\sim 25^{\circ} \mathrm{C}, 45 \mathrm{~s}$ duration) were applied at $5 \mathrm{~min}$ interval, in the presence and in the absence of $10 \mu \mathrm{M}$ PP2. For DRG neurons, similar cold ramps were applied at $10 \mathrm{~min}$ interval, in the presence and in the absence of $10 \mu \mathrm{M}$ PP2, $1 \mu \mathrm{M}$ dasatinib, $1 \mathrm{mM}$ PV or a mixture of PP2 and PV/dasatinib and PV. We also applied (-)-menthol $(200 \mu \mathrm{M})$ at the end of the experiment, to select only $\mathrm{TRPM}^{+}$cells and $50 \mathrm{mM} \mathrm{KCl}$ to identify viable neurons. Fluorescence changes were recorded with a CCD camera (Cohu 4910; Pieper $\mathrm{GmbH}$, Schwerte, Germany). Cells were illuminated at $470 \mathrm{~nm}$ with a Dual OptoLED light source (Cairn Research, Faversham, UK) controlled by the Axon Imaging Workbench 2.2 software (Axon Instruments, Union, CA), which was also used for image acquisition and analysis. The change in the calcium indicator fluorescence was analyzed with custom software and the maximal fluorescence change during stimulation relative to the initial fluorescence ( $\Delta F / F_{0}$, or "amplitude") was measured. A value of $\Delta F / F_{0}>0.1$ was considered a response.

\section{9 | Solutions}

Standard extracellular solution (ECS) contained $140 \mathrm{mM} \mathrm{NaCl}, 4 \mathrm{mM}$ $\mathrm{KCl}, 1 \mathrm{mM} \mathrm{MgCl}$, $2 \mathrm{mM} \mathrm{CaCl}_{2}, 10 \mathrm{mM}$ HEPES, $4.54 \mathrm{mM} \mathrm{NaOH}$ and $5 \mathrm{mM}$ glucose, $\mathrm{pH} 7.4$ at $25^{\circ} \mathrm{C}$. Drugs were added from the following stock solutions: $10 \mathrm{mM} \mathrm{PP2}$ (Sigma) in dimethyl sulphoxide (DMSO), $10 \mathrm{mM}$ dasatinib (Sigma) in DMSO, PV (mixture of $250 \mathrm{mM} \mathrm{Na}_{3} \mathrm{VO}_{4}$ and $35 \% \mathrm{H}_{2} \mathrm{O}_{2}$ ), $200 \mathrm{mM}$ menthol in ethanol, $\mathrm{KCl}$ (standard extracellular solution containing $50 \mathrm{mM} \mathrm{KCl}$ ). The stock solutions were kept at $4^{\circ} \mathrm{C}$ or $-20^{\circ} \mathrm{C}$ and diluted to the desired final concentration in ECS.

\subsection{0 | Data analysis}

All calcium microfluorimetry data were analyzed in OriginPro 8.0 (OriginLab). Results are presented as means $\pm S E M$ or $F / F_{0}$ ratio. Statistical analysis was performed with two-tailed unpaired Student's $t$ test or one-way analysis of variance (ANOVA). For the quantification of VSV-G-TRPM8 tyrosine phosphorylation we used ImageJ.

\section{3 | RESULTS}

\subsection{TRPM8 is tyrosine phosphorylated by Src kinase and partly by TrkA}

To investigate tyrosine phosphorylation of TRPM8 we initially evaluated the effect of PV, a nonspecific inhibitor of PTPs, on cells transfected with human TRPM8 (hTRPM8). Thus, HEK293T cells transiently transfected with VSV-G-tagged hTRPM8 were treated with $1 \mathrm{mM}$ PV for $15 \mathrm{~min}$ and VSV-G-TRPM8 was immunoprecipitated with an anti-VSV-G antibody. Western blot analysis with antipTyr-HRP antibody revealed substantial tyrosine phosphorylation of the TRPM8 channel after PV treatment (Figure 1a). The next step was to identify protein tyrosine kinases (PTKs) involved in tyrosine phosphorylation of hTRPM8. To this aim four human PTKs were tested: three representatives of soluble PTK subclasses ( $\mathrm{Src}, \mathrm{Abl}$, and Btk) and one representative of receptor PTKs (TrkA). HEK293T cells were cotransfected with VSV-G-TRPM8 and one of the mentioned protein tyrosine kinases (Figure 1). VSV-G-TRPM8 was immunoprecipitated with the anti-VSV-G antibody and analyzed by western blot using anti-pTyr-HRP antibody. The strong band detected at $\sim 140 \mathrm{kDa}$ indicates that TRPM8 is tyrosine phosphorylated in the presence of SrcY527F (Figure 1a). Moderate tyrosine phosphorylation of TRPM8 can also be observed when TrkA kinase is overexpressed (Figure 1b), while Abl and Btk overexpression lead to phosphorylation only to a minor extent (Figure 1a).

To further elucidate whether tyrosine phosphorylation of TRPM8 is due to the action of Src, we used PP2. HEK293T cells cotransfected with VSV-G-TRPM8 and SrCY527F were treated with $10 \mu \mathrm{M}$ PP2 for 2, 4, 8 and $24 \mathrm{hr}$, respectively (Figure 2a). Because PP2 was solubilized in DMSO, we have also treated the cells with DMSO for $24 \mathrm{hr}$ to control for a possible effect of DMSO on TRPM8 tyrosine phosphorylation. A significant inhibition of TRPM8 tyrosine phosphorylation can be observed after 2 or $4 \mathrm{hr}$ of PP2 treatment, as well as a complete elimination of tyrosine phosphorylation following $8 \mathrm{hr}$ of PP2 application, compared with the two controls (untreated cells or cells treated with DMSO for $24 \mathrm{hr}$ ), where strong phosphorylation occurs (Figure 2a). After $24 \mathrm{hr}$ of PP2 treatment, a slight phosphorylated band was detected at $\sim 140 \mathrm{kDa}$, possibly due to PP2 degradation. To summarize these results, values of TRPM8 phosphorylation normalized to VSV-G-TRPM8 expression were represented at different incubation time points (Figure 2b). These results indicate that TRPM8 is tyrosine phosphorylated by Src, as treatment of TRPM8-expressing cells with PP2, an Src-specific inhibitor, prevents TRPM8 phosphorylation.

\section{2 | Cold-induced activation of TRPM8 is antagonized by inhibition of Src kinase in cells stably expressing hTRPM8}

Tyrosine phosphorylation of a channel still does not guarantee any modulatory effect of phosphorylation on the channel activity. Thus, because cooling is the main physiological activator of TRPM8, we 
(a)

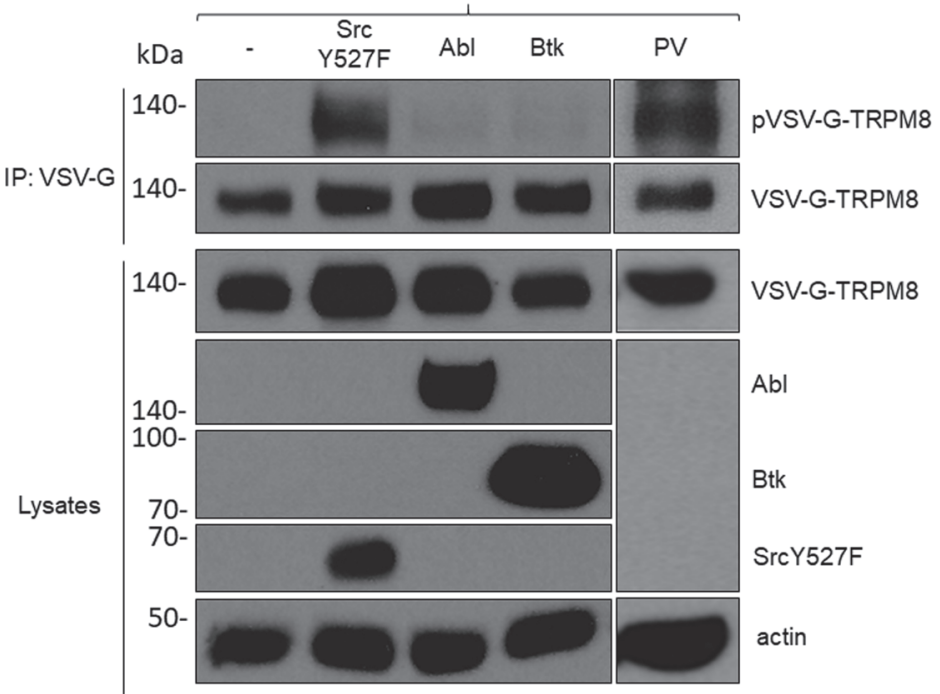

(b)

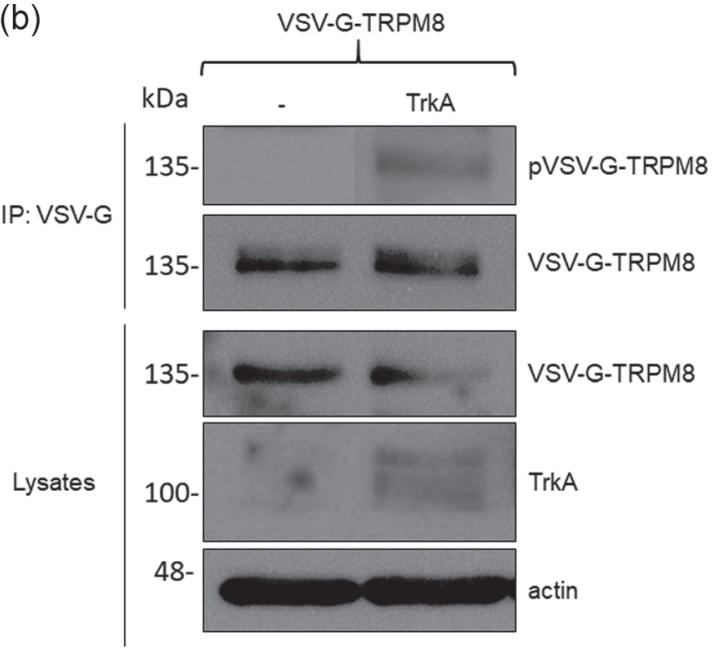

FIGURE 1 TRPM8 is tyrosine phosphorylated after pervanadate treatment, by Src protein tyrosine kinase and partly by TrkA protein tyrosine kinase. (a) Western blot analysis of immunoprecipitated VSV-G-TRPM8 from VSV-G-TRPM8 cells treated with pervanadate or VSV-GTRPM8 + SrcY527F/Abl/Btk cells, demonstrating TRPM8 tyrosine phosphorylation ( 140 kDa; top). Western blot analysis of VSV-G-TRPM8 alone or VSV-G-TRPM8 + SrcY527F/Abl/Btk cell lysates, to demonstrate protein expression after $48 \mathrm{hr}$ of transfection (bottom). The experiments were performed three times and representative data are shown. (b) Western blot analysis of immunoprecipitated VSV-G-TRPM8 from VSV-G-TRPM8 cells and VSV-G-TRPM8 + TrkA cells, demonstrating TRPM8 tyrosine phosphorylation ( 135 kDa; top). Western blot analysis of VSV-G-TRPM8 alone and VSV-G-TRPM8 + TrkA cell lysates, to demonstrate protein expression after 48 hr of transfection (bottom). The experiments were performed two times and representative data are shown. TRPM8, transient receptor potential melastatin type 8

next investigated whether Src kinase is able to modulate coldinduced calcium transients mediated by hTRPM8 stably expressed in HEK293 cells. The HEK293-hTRPM8 cells were also transiently transfected with the constitutively active SrcY527F kinase. Cold ramps (from $\sim 32^{\circ} \mathrm{C}$ to $\sim 25^{\circ} \mathrm{C}, 45$ s duration) were applied six times at 5 min interval (Figures $3 a$ and $3 b$ ) in the presence and in the absence of $10 \mu \mathrm{M}$ PP2. Cold-induced activation of TRPM8 was progressively inhibited by PP2 (Figures $3 a$ and $3 b$ ): the ratio between the amplitudes of the 6th and the 1st cold-induced calcium transients was $0.58 \pm 0.01 \quad(n=437)$ in PP2-treated cells compared with $0.93 \pm 0.01(n=414)$ in control conditions (two-tailed unpaired Student's $t$ test, $p<.0001$; Figure 3c).

HEK293 cells express endogenous Src kinase. Therefore, the above results cumulate the effect of PP2 inhibition on transfected SrcY527F kinase as well as of endogenous Src. To assess the contribution of endogenous Src to these results we repeated the experiment under the same conditions in untransfected-Src HEK293hTRPM8 cells. A similar effect, but of smaller magnitude was observed in HEK293-hTRPM8 cells expressing endogenous Src. Acute application of PP2 after the first cold ramp produced a decrease in the TRPM8-mediated response to cold ramps (Figures $4 \mathrm{a}$ and $4 \mathrm{~b}$ ): the ratio between the amplitudes of the 6 th and the 1st cold-induced calcium transients was $0.80 \pm 0.01(n=319)$ in PP2-treated cells compared with $1.07 \pm 0.01(n=329)$ in control conditions (two-tailed unpaired Student's $t$ test, $p<.0001$; Figure 4c). These calcium imaging experiments demonstrate a relatively fast action of PP2, which is able to produce significant TRPM8 inhibition within $10 \mathrm{~min}$. To confirm this observation, we tried shorter PP2 treatments $(5,10,20$, and $30 \mathrm{~min})$ in
HEK293T cells cotransfected with VSV-G-TRPM8 and SrcY527F or transfected with VSV-G-TRPM8 alone. The bands detected at $\sim 135 \mathrm{kDa}$ show that VSV-G-TRPM8 tyrosine phosphorylation was progressively reduced with increasing PP2 treatment duration in HEK293T cells cotransfected with VSV-G-TRPM8 and SrcY527F ( $63 \mathrm{kDa}$; Figure $3 \mathrm{~d}$ and $3 \mathrm{e})$. Importantly, VSV-G-TRPM8 was constitutively tyrosine phosphorylated by the endogenous Src protein kinase (c-Src, $\sim 63 \mathrm{kDa}$ ) in HEK293T cells transfected with VSV-GTRPM8 alone and PP2 treatment antagonized this action (Figure 4d and $4 \mathrm{e}$ ). We also checked the phosphorylation of Src kinase at tyrosine 418 (Tyr 416 on chicken Src), an important residue for the kinase activity. We observed that both SrcY527F and c-Src are phosphorylated at Tyr418 ( 63 kDa; Figures 3d and 4d), that PP2 partly inhibits the phosphorylation of Tyr418 in HEK293T cells cotransfected with VSV-G-TRPM8 and SrcY527F (Figure 3d). The results described above show that inhibition of Src-mediated tyrosine phosphorylation suppresses cold-activation of TRPM8 in HEK293 cells stably expressing TRPM8.

\subsection{Cold-induced activation of TRPM8 is reduced by RNA interference against endogenous Src kinase in cells stably expressing TRPM8}

The previous findings suggest that the inhibitory effect of PP2 on the cold activation of recombinant human TRPM 8 could be attributed at least in part to its inhibition of endogenous Src. To further investigate whether the PP2-induced reduction of TRPM8-mediated cold responses might be caused by the inhibition of Src kinase, we 
(a)

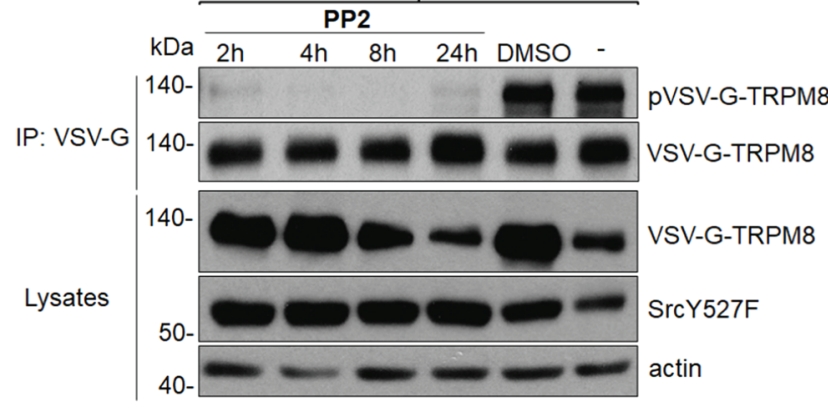

(b)

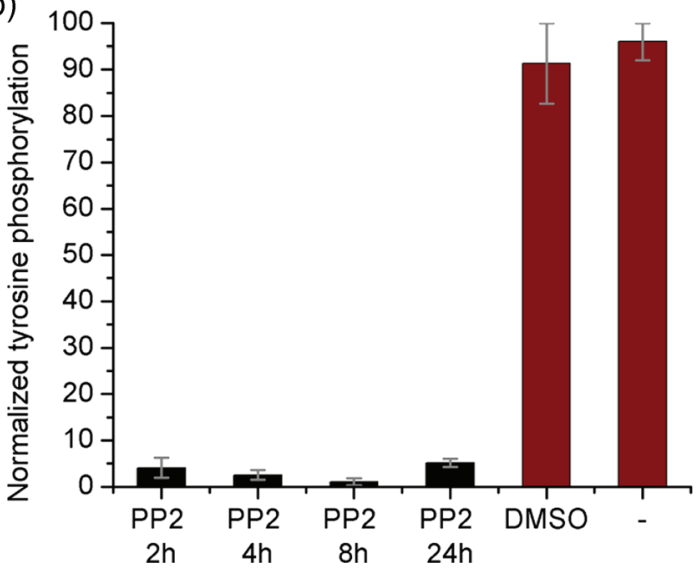

FIGURE 2 PP2 treatment prevents Src-induced TRPM8 tyrosine phosphorylation. (a) Western blot analysis of immunoprecipitated VSVG-TRPM8 from cells co-expressing VSV-G-TRPM8 and SrcY527F, untreated or treated with DMSO for $24 \mathrm{hr}$ or with $10 \mu \mathrm{M}$ PP2 for 2, 4, 8 and $24 \mathrm{hr}$ respectively, showing TRPM8 tyrosine phosphorylation ( $140 \mathrm{kDa}$; top). Western blot assay using anti-VSV-G, anti-Src, and anti-actin antibodies, to verify protein expression (bottom). (b) Relative quantification of TRPM8 tyrosine phosphorylation normalized to VSVG-TRPM8 expression. Data are presented as pVSV-G-TRPM8/VSV-GTRPM8 mean \pm SEM. DMSO, dimethyl sulphoxide; TRPM8, transient receptor potential melastatin type 8

silenced Src expression in HEK293-hTRPM8 cells using shortinterfering RNA against Src kinase (Src_siRNA). We then monitored the effect of PP2 on cold-induced calcium transients in cells transfected with Src_siRNA compared with cells transfected with scrambled RNA. Src kinase protein expression was reduced in Src_siRNA-transfected cells, compared with control untransfected cells or scrambled RNA-transfected cells (Figures 5a and 5b). The bands detected at $\sim 63 \mathrm{kDa}$ show that Src kinase is phosphorylated at Tyr418 in control cells and RNA-trasfected cells, demonstrating the kinase activity (Figure $5 \mathrm{a}$ ). Cold ramps (from $\sim 32^{\circ} \mathrm{C}$ to $\sim 25^{\circ} \mathrm{C}, 45 \mathrm{~s}$ duration) were applied seven times at 5 min interval (Figure $5 \mathrm{c}$ ), in the presence and in the absence of $10 \mu \mathrm{M}$ PP2 (acutely applied after the second cold stimulus). The initial response to cold stimulation was significantly reduced in Src-siRNA-transfected cells, compared with those transfected with scrambled RNA $(0.61 \pm 0.01, n=680$, compared with $0.66 \pm 0.01, n=725$, two-tailed unpaired Student's $t$ test, $p<.0001)$. Tachyphylaxis of cold-induced calcium transients occurred in the presence of PP2 in HEK293-hTRPM8 cells transfected with both Src_siRNA and scrambled RNA, but the effect was more pronounced in scrambled RNA-transfected cells (Figure 5c).

In Src_siRNA-transfected cells there was a reduction in the ratio between the amplitudes of the 7th and the 1st cold-induced calcium transients of ca. $19 \%$ between control $(1.12 \pm 0.02, n=345)$ and PP2treated cells $(0.91 \pm 0.01, n=335)$. In scrambled RNA-transfected cells, the reduction in amplitude ratio (7th to 1st cold response) was substantially larger $(27 \%$, from $1.00 \pm 0.01, n=389$, to $0.73 \pm 0.01$, $n=336$; one-way ANOVA with independent samples, $p<.0001$; Figure $5 d)$. This experiment shows that by silencing endogenous Src the PP2induced inhibition of thermal activation of TRPM8 is significantly reduced.

\section{4 | PP2-induced inhibition of TRPM8 channel activity in cultured rat DRG neurons is reduced in the presence of PV}

We investigated whether the stimulatory effect of tyrosine phosphorylation on TRPM8 channel activity, which we observed in HEK293-hTRPM8 cells, also occurs in rat DRG neurons. To address this question, we carried out calcium microfluorimetry experiments on rat DRG neurons in primary culture, in which both TRPM8 and Src kinase are natively expressed. Cold ramps (from $\sim 32^{\circ} \mathrm{C}$ to $\sim 25^{\circ} \mathrm{C}, 45 \mathrm{~s}$ duration), followed by menthol application were used to activate native TRPM8, while PP2 $(10 \mu \mathrm{M})$ and PV (1 $\mathrm{mM})$ were used to inhibit Src kinase and PTPs, respectively. We only used for analysis cold-sensitive neurons which also responded to menthol, indicating expression of TRPM8 channels. There was no difference in terms of cold sensitivity or tachyphylaxis of the cold response between control neurons and those treated with PV, and therefore we pooled these cells together in our analysis. PP2induced tachyphylaxis of cold-induced calcium transients was significantly less pronounced in the presence of PV, than in the absence of the PTP inhibitor (Figure 6a). The ratio between the amplitudes of the 2 nd and 1st calcium transients was $0.82 \pm 0.05$ $(n=21)$ in the presence of both PP2 and PV, compared with $0.60 \pm 0.06(n=26)$ in the presence of PP2 only (two-tailed unpaired Student's $t$ test, $p<.01$ ). In control conditions (untreated neurons and neurons treated with PV), the same ratio was $1.05 \pm 0.04$ $(n=45)$, significantly different compared with PP2-treated neurons (two-tailed unpaired Student's $t$ test, $p<.0001$ ) and PV+PP2treated neurons (two-tailed unpaired Student's $t$ test, $p<.001$; Figure 6b). For the third cold response, the effect of PP2 alone was still significant compared with control (the $3 \mathrm{rd}$ to 1 st response ratio was $0.64 \pm 0.07, n=26$ for PP2-treated cells, compared with $0.97 \pm 0.06, n=45$, for control cells, two-tailed unpaired Student's $t$ test, $p<.001$ ). Application of PP2 in the presence of PV diminished the tachyphylaxis: the 3 rd to 1 st response ratio was $0.81 \pm 0.06$, $n=21$, not significantly different from PP2-treated or control cells. Thus, TRPM8-mediated calcium transients in cultured rat DRG neurons are inhibited by PP2 treatment of the cells, an effect that is antagonized by inhibition of PTPs. 
(a)

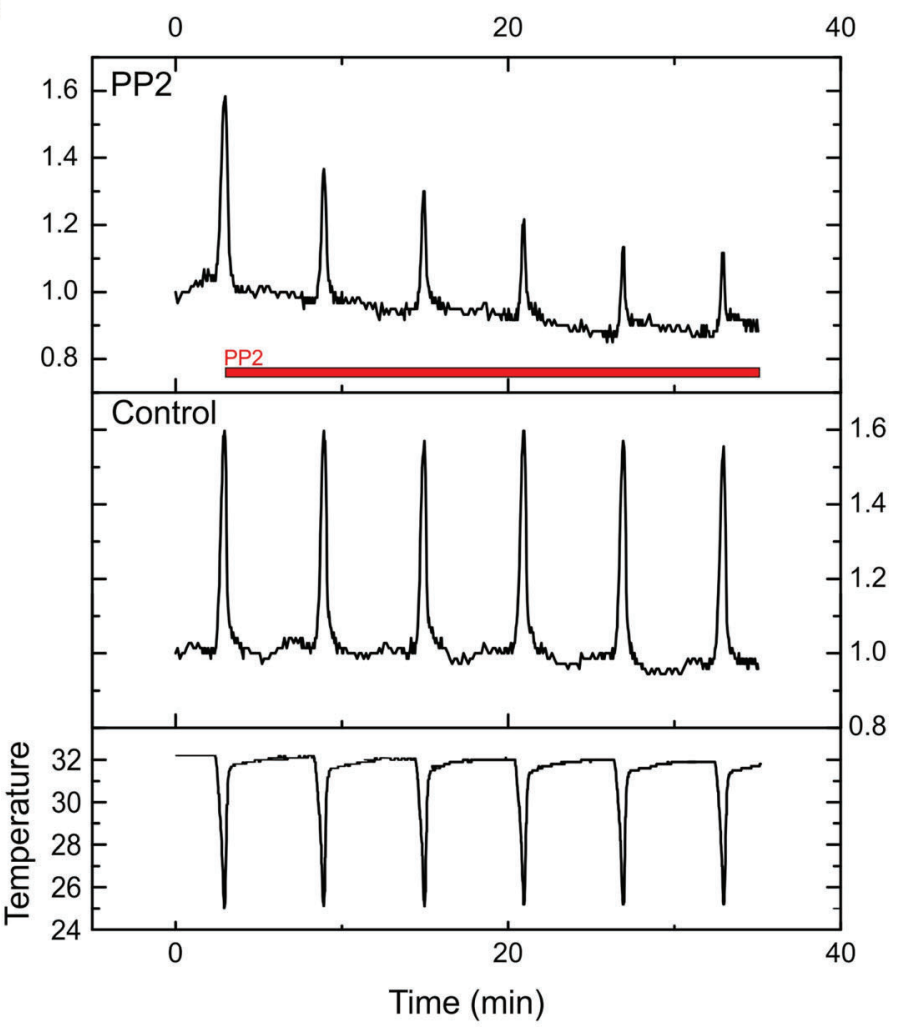

(d)

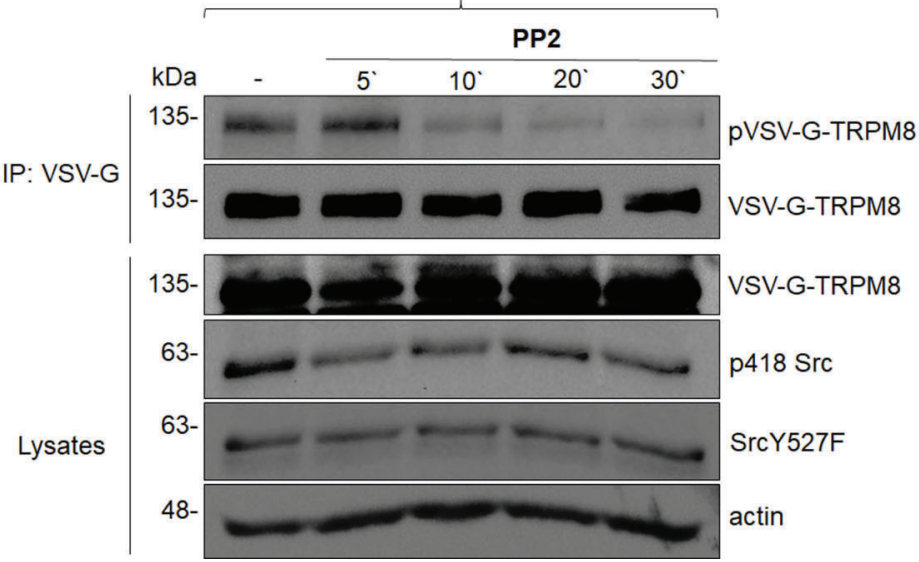

(b)

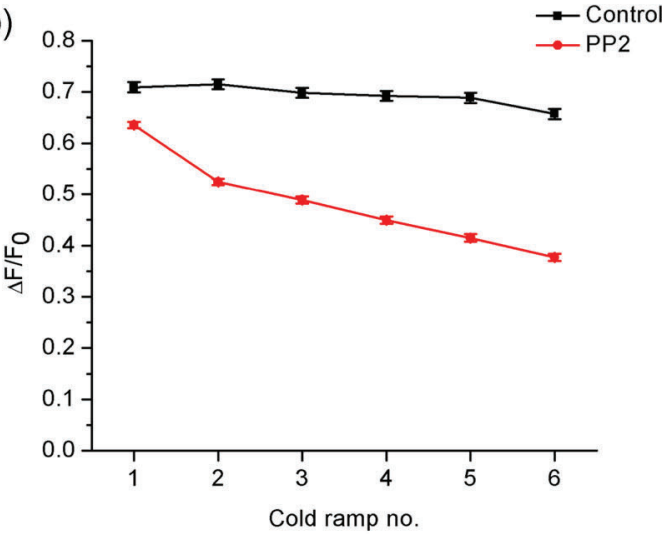

(c)

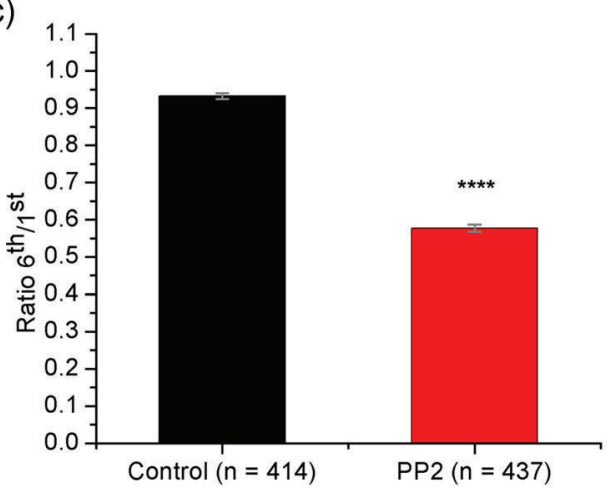

(e)

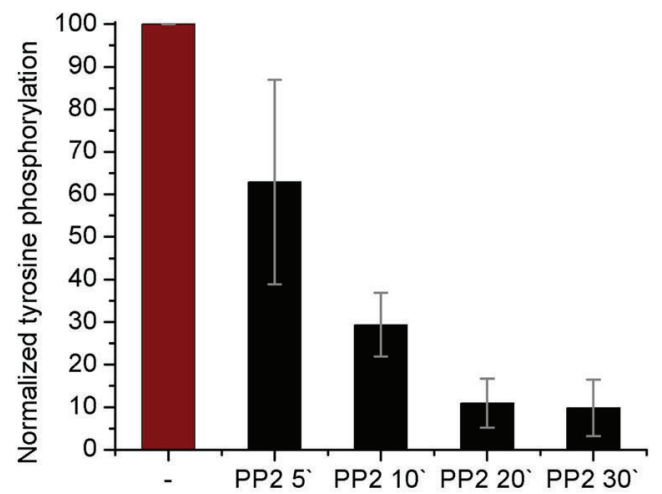

FIGURE 3 Pharmacological inhibition of Src tyrosine kinase suppresses phosphorylation and cold-induced activation of TRPM8 in HEK293hTRPM8 cells transiently transfected with SrcY527F kinase. (a) Illustrative examples of traces from individual cells showing cold-induced calcium transients, in the presence (upper trace) and in the absence of PP2 (middle trace). A temperature recording during the stimulation protocol consisting in six successive cold ramps is also shown (bottom trace). (b) Mean $\Delta F / F_{0}$ of cold-induced calcium transients in control conditions (black, $n=414$ ) and during PP2 $(10 \mu \mathrm{M})$ application (red, $n=437)$. Data are presented as $\Delta F / F_{0}$ mean $\pm S E M$. (c) Comparison of the ratio between the amplitudes of the 6th and the 1st cold-induced calcium transients in cells treated with PP2 (red) or in control conditions (black) for the experiment illustrated in A ( ${ }^{* * * *} p<.0001$, two-tailed unpaired Student's $t$ test). (d) Western blot analysis of immunoprecipitated VSV-G-TRPM8 from cells co-expressing VSV-G-TRPM8 and SrcY527F, untreated or treated with PP2 $10 \mu M$ for 5, 10, 20, and 30 min respectively, showing TRPM8 tyrosine phosphorylation ( 135 kDa; top). Western blot assay, with anti-VSV-G, anti-Src (phospho418), anti-Src and anti-actin antibodies to demonstrate protein expression and the phosphorylation of SrcY527F kinase at tyrosine 418 (bottom). (e) Relative quantification of TRPM8 tyrosine phosphorylation normalized in respect to VSV-G-TRPM8 immunoprecipitated from HEK293T cells coexpressing VSV-G-TRPM8 and SrcY527F. Data are presented as pVSV-G-TRPM8/VSV-G-TRPM8 mean \pm SEM. TRPM8, transient receptor potential melastatin type 8 
(a)

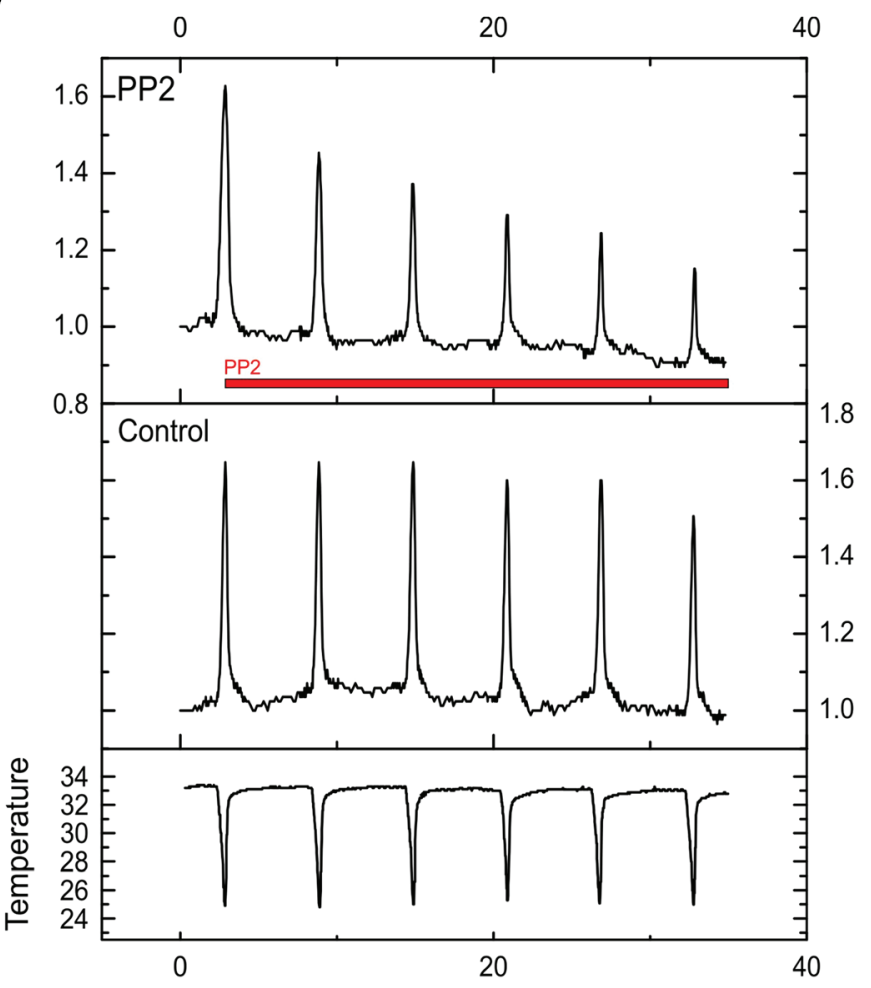

(d)

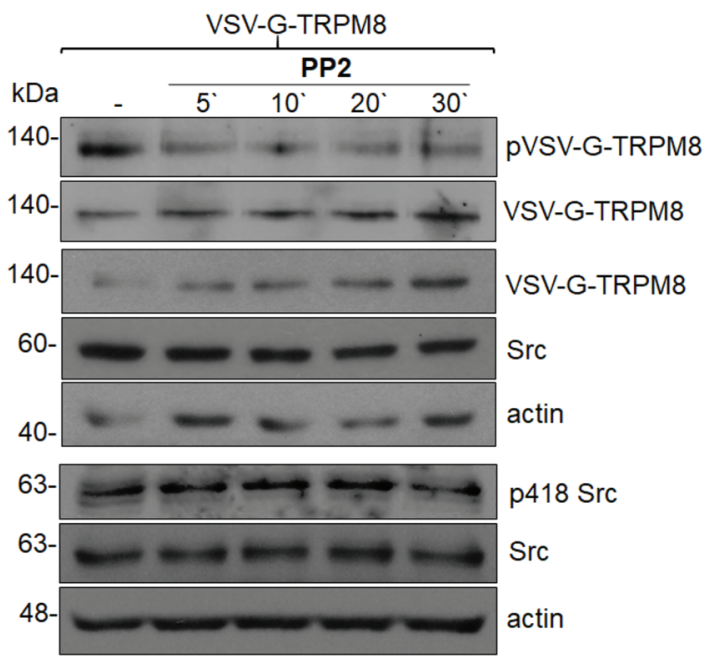

(b)

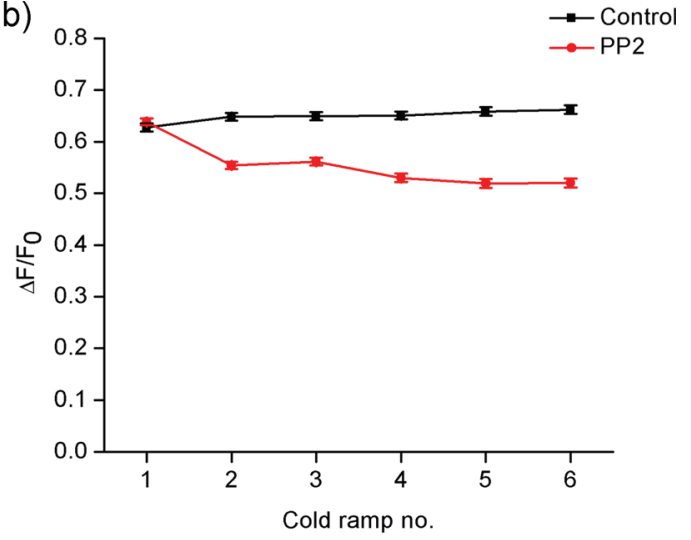

(c)

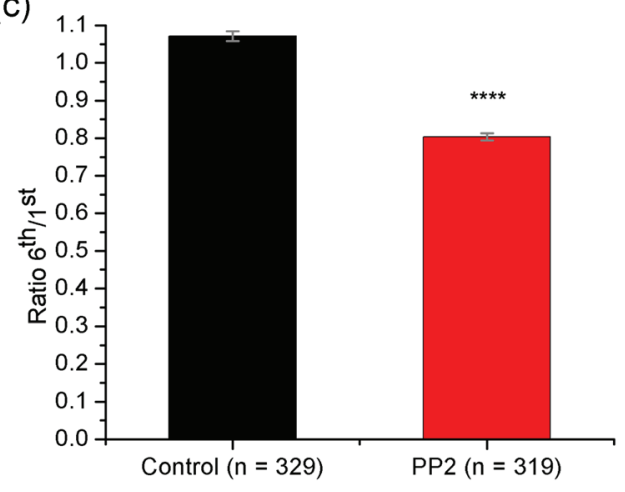

(e)

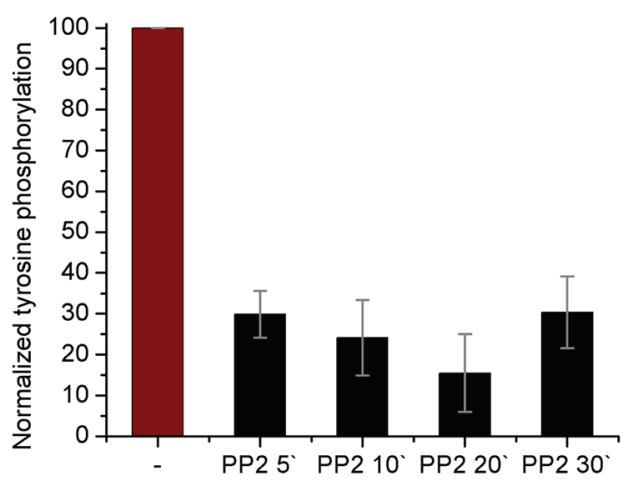

FIGURE 4 Pharmacological inhibition of endogenous Src tyrosine kinase suppresses phosphorylation and cold-induced activation of TRPM8. (a) Illustrative examples of traces from individual cells showing cold-induced calcium transients, in the presence (upper trace) and in the absence of PP2 (middle trace). A temperature recording during the stimulation protocol consisting in six successive cold ramps is also shown (bottom trace). (b) Mean $\Delta F / F_{0}$ of cold-induced calcium transients in control conditions (black, $\left.n=329\right)$ and during PP2 $(10 \mu M)$ application (red, $\left.n=319\right)$. Data are presented as $\triangle F / F_{0}$ mean $\pm S E M$. (c) Comparison of the ratio between the amplitudes of the 6th and the 1st cold-induced calcium transients in cells treated with PP2 (red) or in control conditions (black) for the experiment illustrated in A $\left({ }^{* * * *} p<.0001\right.$, two-tailed unpaired Student's $t$ test). (d) Western blot analysis of immunoprecipitated VSV-G-TRPM8 from cells expressing VSV-G-TRPM8, untreated or treated with PP2 $10 \mu \mathrm{M}$ for 5, 10, 20, and $30 \mathrm{~min}$, respectively, showing TRPM8 tyrosine phosphorylation ( 140 kDa; top). Western blot assay, with anti-VSV-G, anti-Src, and anti-actin antibodies to demonstrate the protein expression (middle). Western blot assay, with anti-Src (phospho418), anti-Src and anti-actin antibodies to demonstrate the phosphorylation of endogenous Src kinase at tyrosine 418 (bottom). (e) Relative quantification of TRPM8 tyrosine phosphorylation normalized to VSV-G-TRPM8 immunoprecipitated from HEK293T cells expressing VSV-GTRPM8 and endogenous Src. Data are presented as pVSV-G-TRPM8/VSV-G-TRPM8 mean \pm SEM. TRPM8, transient receptor potential melastatin type 8 
(a)
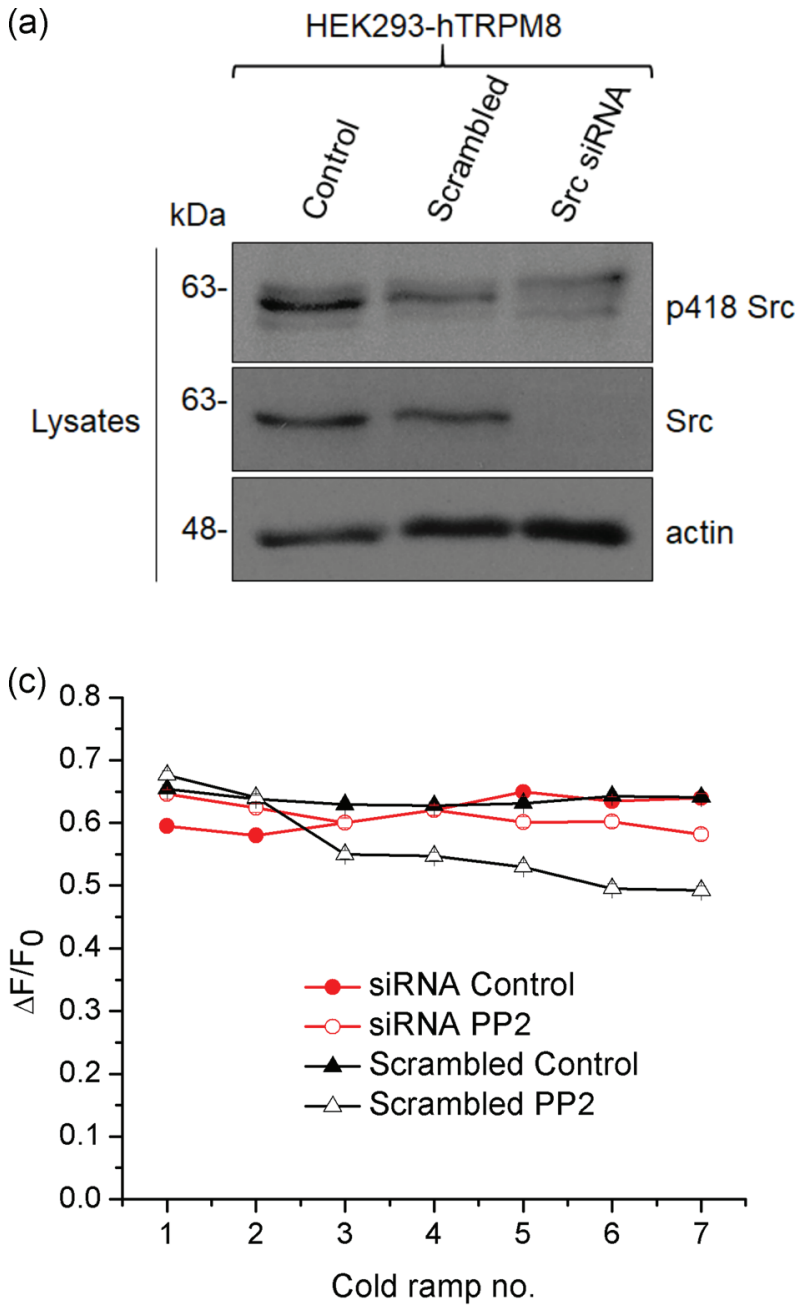

(b)

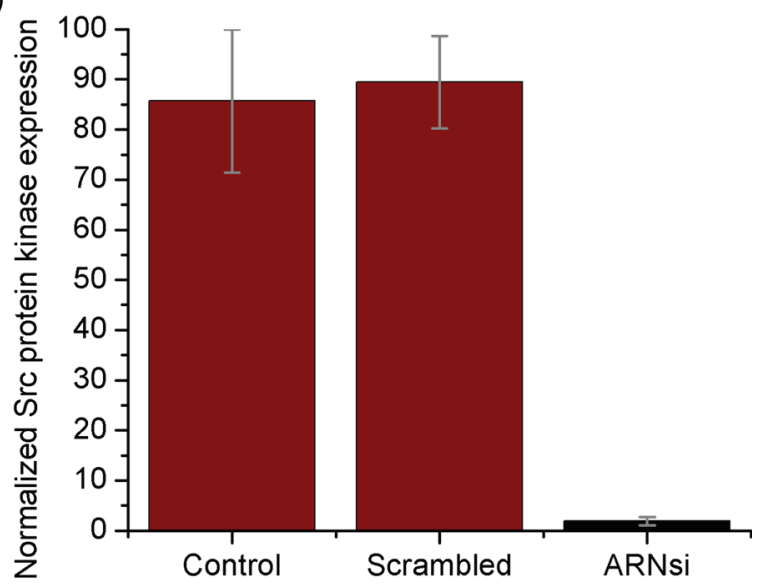

(d)

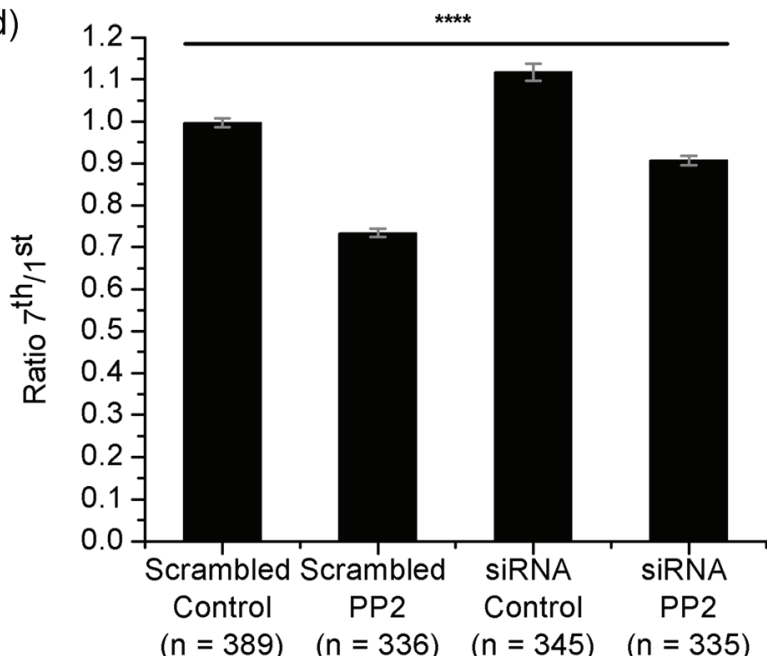

FIGURE 5 Src silencing diminishes the effect of PP2 on cold-induced calcium transients in HEK293-hTRPM8 cells. (a) Western blot assay, using anti-Src, anti-Src (phospho418) and anti-actin antibodies, to demonstrate the protein expression and the phosphorylation of endogenous Src kinase at tyrosine 418. Src kinase expression was reduced in Src_siRNA-transfected cells after $96 \mathrm{hr}$, compared with control cells or scrambled RNA-transfected cells. (b) Relative quantification of Src protein tyrosine kinase normalized to actin or GAPDH expression in HEK293-hTRPM8 cells. Data are presented as ratio mean $\pm S E M$. (c) Mean $\triangle F / F_{0}$ for TRPM8-mediated cold-induced calcium transients in four conditions: (A) Src_siRNA-transfected, control (red filled circles), (B) Src_siRNA-transfected, PP2-treated (red open circles), (C) Scrambled RNAtransfected, control (black filled triangles) and (D) Scrambled RNA-transfected, PP2-treated (black open triangles). Values represent mean $\triangle F /$ $F_{0} \pm S E M$. (d) Comparison of the ratio between the amplitudes of the 7th and the 1st cold-induced calcium transients for the experiment illustrated in (c). ANOVA, analysis of variance; GAPDH, glyceraldehyde 3-phosphate dehydrogenase; TRPM8, transient receptor potential melastatin type $8\left(^{* * *} p<.0001\right.$, one-way ANOVA for independent samples)

Dasatinib is also an Src kinase inhibitor, more selective compared with PP2 (Brandvold, Steffey, Fox, \& Soellner, 2012). We monitored the effect of dasatinib, alone and in the presence of $\mathrm{PV}$, on coldinduced calcium transients in cultured rat DRG neurons compared with control neurons (untreated neurons and neurons treated with PV). Cold-induced activation of TRPM8 was inhibited by dasatinib (Figure 6): the ratio between the amplitudes of the 2 nd and 1 st coldinduced calcium transients was $0.87 \pm 0.04(n=31)$ in dasatinibtreated neurons compared with $1.05 \pm 0.04(n=45)$ in control conditions (two-tailed unpaired Student's $t$ test, $p<.01$ ). PV completely prevented the inhibitory effect of dasatinib (the 2 nd to 1 st response ratio was $1.05 \pm 0.04, n=25$, in the presence of $P V$, not significantly different from control). The effect of dasatinib alone was still significant compared with $\mathrm{PV}+$ dasatinib-treated neurons for the third cold response (the $3 r d$ to 1 st response ratio was $0.86 \pm 0.06, n=31$, for dasatinib-treated cells, compared with $1.01 \pm 0.05, n=25$, for PV + dasatinib-treated neurons, two-tailed unpaired Student's $t$ test, $p<.05$ ), but not significantly different from control cells (Figure 6b).

\section{4 | DISCUSSION}

Our results demonstrate that Src tyrosine kinase phosphorylates TRPM8 and modulates the cold-induced activation of the channel. The amplitude of TRPM8-mediated cold-induced calcium transients was reduced in the presence of the selective Src inhibitor PP2 in 
(a)
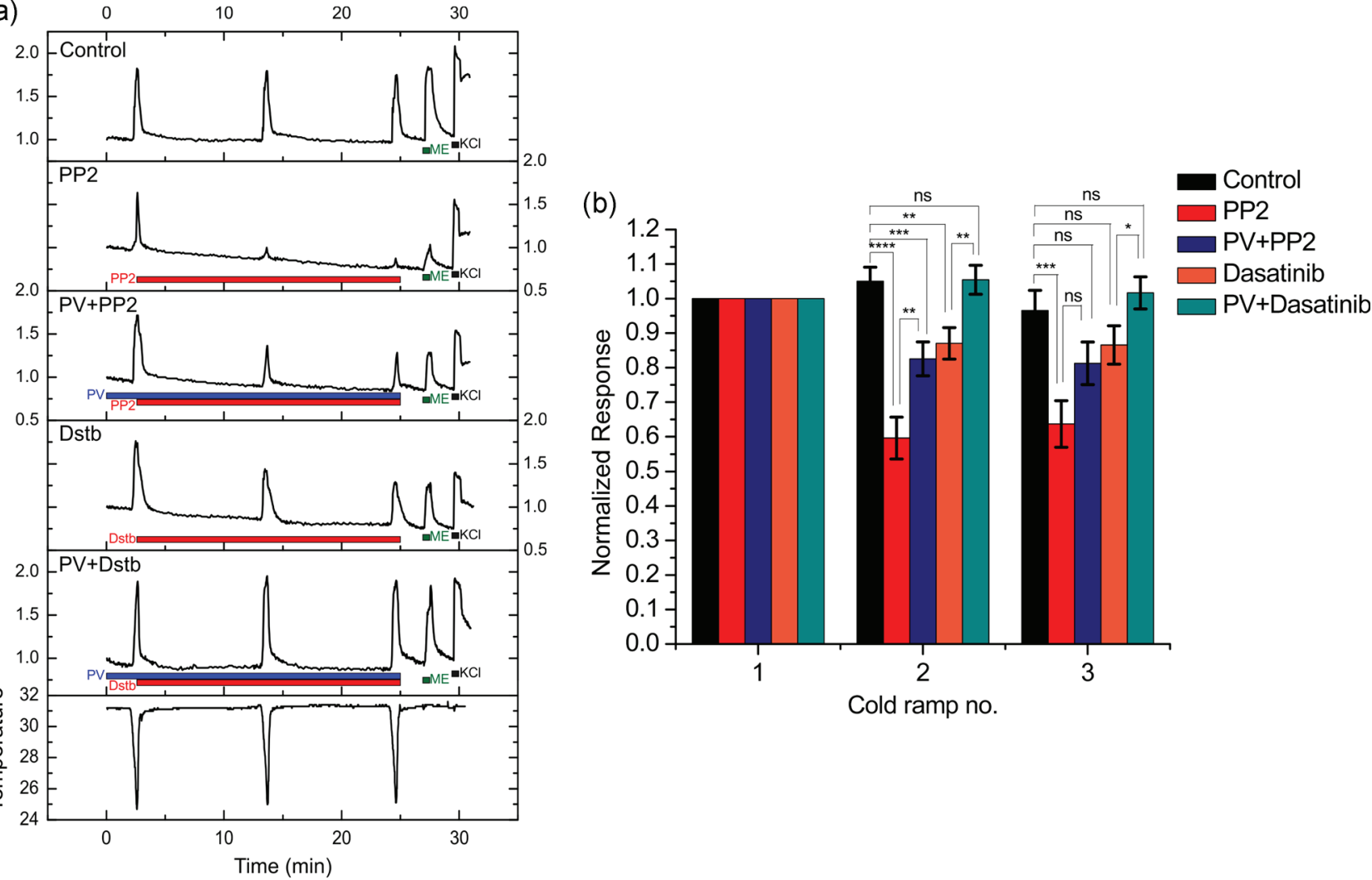

FIGURE 6 PP2/dasatinib-induced inhibition of TRPM8-mediated calcium transients in cultured rat DRG neurons is reduced in the presence of the PTP inhibitor PV. (a) DRG neurons were challenged with three cold ramps (from $\sim 32^{\circ} \mathrm{C}$ to $\sim 25^{\circ} \mathrm{C}, 45 \mathrm{~s}$ duration, at 5 min interval), followed by (-)-menthol $(200 \mu \mathrm{M}, 30 \mathrm{~s})$ and $\mathrm{KCl}(50 \mathrm{mM}, 30 \mathrm{~s})$. Examples of traces from individual rat DRG neurons in control conditions (untreated neurons), treated with PP2, with both PP2 and PV, with dasatinib and with both dasatinib and PV. (b) Statistical analysis of the results illustrated in part (a) for the five different conditions: (A) control or PV-treated ( $n=45$; black), (B) treated with PP2 only ( $n=26$; red), (C) treated with both PP2 and PV ( $n=21$; blue), (D) treated with dasatinib only $(n=31$; orange) and (E) treated with both dasatinib and PV ( $n=25$; green). Values represent mean \pm SEM responses normalized to the first cold ramp. DRG, dorsal root ganglion; PV, pervanadate; PTP, protein tyrosine phosphatase; TRPM8, transient receptor potential melastatin type $8\left({ }^{* * * *} p<.0001\right.$, two-tailed unpaired Student's $t$ test, ${ }^{* * *} p<.001$, two-tailed unpaired Student's $t$ test, ${ }^{* *} p<.01$, two-tailed unpaired Student's $t$ test, ${ }^{*} p<.05$, two-tailed unpaired Student's $t$ test, ns $p>.05$, two-tailed unpaired Student's $t$ test)

HEK293 cells co-expressing human TRPM8 and a constitutively active isoform of Src. A similar, albeit less pronounced effect was produced by PP2 in HEK293 cells expressing just hTRPM8, indicating that inhibition of endogenous Src is sufficient to produce functional downregulation of the channel. Interestingly, the inhibition of TRPM8 phosphorylation by PP2 in HEK293 cells cotransfected with hTRPM8 and Src Y527F was almost complete (Figures $3 \mathrm{~d}$ and $3 \mathrm{e}$ ) while the effect of PP2 on endogenous Src led to only approx. $70 \%$ inhibition of TRPM8 phosphorylation (Figures $4 \mathrm{~d}$ and $4 \mathrm{e}$ ). The reason for this difference is unclear. However, in agreement with this difference, there was a stronger effect of PP2 on TRPM8 function in the first case (leading to an approx. $38 \%$ reduction in response amplitude to cold stimulation), compared with the second case (endogenous Src), where the inhibition induced by PP2 was of approx. 25\%. A stronger reduction of TRPM8 phosphorylation was associated with a stronger inhibition of TRPM8 function.

The cold-induced activity of natively expressed TRPM8 in cultured rat primary afferent neurons was also decreased by acutely applied PP2, and a similar but less potent effect was induced by another selective Src inhibitor, dasatinib. In both cases, the negative modulatory action of the Src inhibitors on TRPM8 was antagonized by $\mathrm{PV}$, a protein tyrosine phosphatase inhibitor. The fact that two different chemically unrelated Src inhibitors produce a similar effect on TRPM8-channel function confirms that Src inhibition is responsible for this action, and not a direct antagonistic action of the two molecules on the channel itself. This conclusion is strengthened by two additional observations: that the effects of PP2 and dasatinib are antagonized by PV, and that the negative modulation of recombinant hTRPM8 by PP2 is abolished following downregulation of endogenous Src by RNA interference.

c-Src is a proto-oncogene known for its involvement in transformation, migration, invasion, and proliferation of tumor cells. Elevated c-Src activity has been reported in tumors from colon, liver, breast, pancreas, prostate, and lung (Dehm \& Bonham, 2004; Nam et al., 2005). On the other hand, increased levels of TRPM8 expression were observed in prostate cancer, osteosarcoma, pancreatic adenocarcinoma, breast ductal adenocarcinoma (Hantute-Ghesquier et al., 2018), thus suggesting that c-Src and TRPM8 may play synergistic roles in the progression 
of some tumor forms. However, TRPM8 cannot be simply considered as an oncogene. The complexity of its functional implication in cancer is illustrated by its role in prostate cancer: while TRPM8 expression is correlated with the transformation of malignant cells, in androgendependent prostate carcinoma it inhibits the migration of tumor cells due to inactivation of adhesion kinase (Hantute-Ghesquier et al., 2018). Our results show that both Src and TrkA kinases can phosphorylate TRPM8, but the efficiency of Src-mediated phosphorylation seems to be substantially higher. In addition, the almost complete fading of TRPM8 phosphorylation after $8 \mathrm{hr}$ treatment with PP2 (Figure 2) suggests that TRPM8 is tyrosine phosphorylated exclusively by a member of the Src subfamily of kinases. However, we cannot rule out that activation of Src kinases results from their crosstalk with TrkA. Indeed, a large number of tyrosine kinase receptors were proved to be activators of Src and of its oncogenic transduction pathways (Mezquita, Mezquita, Pau, Mezquita, \& Mezquita, 2014).

Our results are also relevant for the understanding of the role played by TRPM8 in inflammatory pain. Behavioral investigation of TRPM8-null mutant mice revealed an important contribution of TRPM8 to the development of cold allodynia following paw injection of Complete Freund's Adjuvant (CFA; Colburn et al., 2007). However, this is not easily reconciled with the fact that many different inflammatory mediators, such as bradykinin, prostaglandin E2, NGF, and extracellular protons, are known to downregulate TRPM8 function (Andersson, Chase, \& Bevan, 2004; Linte, Ciobanu, Reid, \& Babes, 2007; Liu \& Qin, 2005; Premkumar et al., 2005). Interestingly, CFA-induced inflammatory pain appears to be dependent on the activation of c-Src kinase (Nagae et al., 2006), and the potentiation of TRPM8 activity upon Srcmediated tyrosine phosphorylation reported here may explain the involvement of this channel in the CFA-induced inflammatory cold hypersensitivity.

The molecular mechanism of TRPM8 activation by cold is not fully understood, but it has been shown that TRPM8 reconstituted in planar lipid bilayer is gated by cold (Zakharian, Cao, \& Rohacs, 2010). Thus, it was elegantly proved that TRPM 8 is directly activated by cooling, without the involvement of any external signaling cascades. The authors also provided evidence that colddriven channel openings were accompanied by substantial variations in enthalpy and entropy, indicating significant conformational rearrangements in the protein structure. Our results, showing that Src-mediated phosphorylation of TRPM8 potentiates cold-induced activation of TRPM8, could be explained in terms of these findings: tyrosine phosphorylation is likely to induce conformational changes leading to increased channel activity. The tyrosine residues potentially involved in such modifications could be located in the C-terminal region, given that this region was reported to be implicated in the cold-induced gating of TRPM8 (Brauchi, Orta, Salazar, Rosenmann, \& Latorre, 2006). Other putative tyrosine residues involved in the modulation of TRPM 8 channel activity could be the conserved residues $\mathrm{Tyr}^{826}$ and $\mathrm{Tyr}^{836}$ situated on the S4 transmembrane helix, according to the recently published TRPM8 structure (Yin et al., 2018). Mutations neutralizing charged amino acids within the S4 helix and the S4-S5 linker region reduced the gating charge of TRPM8 (Voets, Owsianik, Janssens, Talavera, \& Nilius, 2007). Conceivably, introducing a negatively charged phosphate moiety on a tyrosine residue located in S4 would alter the voltage dependence of activation. Further in-depth studies are needed to identify the position of the Src-phosphorylated tyrosine residue(s) as well as to elucidate the structural basis of TRPM8 coldinduced activation and its modulation by tyrosine phosphorylation.

\section{ACKNOWLEDGMENTS}

A. M., T. S., C. N., and A. B. were funded by grant PNIII-P4-ID-PCE2016-0475 from the Romanian Ministry of Research and Innovation.

\section{CONFLICT OF INTERESTS}

The authors declare no potential conflict of interests with respect to the authorship and/or publication of this article.

\section{AUTHOR CONTRIBUTIONS}

A. B. and S. E. S. designed the experiments, wrote the manuscript, conducted the experiments and revised the manuscript. A. M., T. S., L. M., M. M., A. I., and C. N. contributed to experimental work and data analyses. All authors have read and approved the final manuscript.

\section{DATA AVAILABILITY STATEMENT}

The data that support the findings of this study are available from the corresponding authors upon reasonable request.

\section{ORCID}

Alexandru Babes (D) http://orcid.org/0000-0002-7110-6908 Stefan Eugen Szedlacsek (D) http://orcid.org/0000-0002-3416-5036

\section{REFERENCES}

Andersson, D. A., Chase, H. W., \& Bevan, S. (2004). TRPM8 activation by menthol, icilin, and cold is differentially modulated by intracellular $\mathrm{pH}$. Journal of Neuroscience, 24(23), 5364-5369.

Asuthkar, S., Demirkhanyan, L., Mueting, S. R., Cohen, A., \& Zakharian, E. (2017). High-throughput proteome analysis reveals targeted TRPM8 degradation in prostate cancer. Oncotarget, 8(8), 12877-12890.

Asuthkar, S., Demirkhanyan, L., Sun, X., Elustondo, P. A., Krishnan, V., Baskaran, P., ... Zakharian, E. (2015). The TRPM8 protein is a testosterone receptor: II. Functional evidence for an ionotropic effect of testosterone on TRPM8. Journal of Biological Chemistry, 290(5), 2670-2688.

Asuthkar, S., Velpula, K. K., Elustondo, P. A., Demirkhanyan, L., \& Zakharian, E. (2015). TRPM 8 channel as a novel molecular target in androgenregulated prostate cancer cells. Oncotarget, 6(19), 17221-17236.

Babes, A., Ciobanu, A.C., Neacsu, C., \& Babes, R. M. (2011). TRPM8, a sensor for mild cooling in mammalian sensory nerve endings. Current Pharmaceutical Biotechnology, 12(1), 78-88. 
Bautista, D. M., Siemens, J., Glazer, J. M., Tsuruda, P. R., Basbaum, A. I., Stucky, C. L., ... Julius, D. (2007). The menthol receptor TRPM8 is the principal detector of environmental cold. Nature, 448(7150), 204-208.

Brandvold, K. R., Steffey, M. E., Fox, C. C., \& Soellner, M. B. (2012). Development of a highly selective c-Src kinase inhibitor. ACS Chemical Biology, 7(8), 1393-1398.

Brauchi, S., Orta, G., Salazar, M., Rosenmann, E., \& Latorre, R. (2006). A hot-sensing cold receptor: C-terminal domain determines thermosensation in transient receptor potential channels. Journal of Neuroscience, 26(18), 4835-4840.

Bödding, M., Wissenbach, U., \& Flockerzi, V. (2007). Characterisation of TRPM8 as a pharmacophore receptor. Cell Calcium, 42(6), 618-628.

Colburn, R. W., Lubin, M. L., Stone, D. J., Wang, Y., Lawrence, D., D’Andrea, M. R., ... Qin, N. (2007). Attenuated cold sensitivity in TRPM8 null mice. Neuron, 54(3), 379-386.

Cucu, D., Chiritoiu, G., Petrescu, S., Babes, A., Stanica, L., Duda, D. G., ... Popescu, I. (2014). Characterization of functional transient receptor potential melastatin 8 channels in human pancreatic ductal adenocarcinoma cells. Pancreas, 43(5), 795-800.

Dehm, S. M., \& Bonham, K. (2004). SRC gene expression in human cancer: The role of transcriptional activation. Biochemistry and Cell Biology, 82(2), 263-274.

Dhaka, A., Murray, A. N., Mathur, J., Earley, T. J., Petrus, M. J., \& Patapoutian, A. (2007). TRPM8 is required for cold sensation in mice. Neuron, 54(3), 371-378.

Fernández, J. A., Skryma, R., Bidaux, G., Magleby, K. L., Scholfield, C. N., McGeown, J. G., ... Zholos, A. V. (2011). Voltage- and cold-dependent gating of single TRPM8 ion channels. Journal of General Physiology, 137(2), 173-195.

Fernández, J. A., Skryma, R., Bidaux, G., Magleby, K. L., Scholfield, C. N., McGeown, J. G., ... Zholos, A. V. (2012). Short isoforms of the cold receptor TRPM8 inhibit channel gating by mimicking heat action rather than chemical inhibitors. Journal of Biological Chemistry, 287(5), 2963-2970.

Hantute-Ghesquier, A., Haustrate, A., Prevarskaya, N., \& Lehen'kyi, V. (2018). TRPM family channels in cancer. Pharmaceuticals, 11(2), 58.

Huang, J., Zhang, X., \& McNaughton, P. A. (2006). Modulation of temperature-sensitive TRP channels. Seminars in Cell \& Developmental Biology, 17(6), 638-645.

Knowlton, W. M., Bifolck-Fisher, A., Bautista, D. M., \& McKemy, D. D. (2010). TRPM8, but not TRPA1, is required for neural and behavioral responses to acute noxious cold temperatures and cold-mimetics in vivo. Pain, 150(2), 340-350.

Linte, R. M., Ciobanu, C., Reid, G., \& Babes, A. (2007). Desensitization of cold- and menthol-sensitive rat dorsal root ganglion neurones by inflammatory mediators. Experimental Brain Research, 178(1), 89-98.

Liu, B., \& Qin, F. (2005). Functional control of cold- and menthol-sensitive TRPM8 ion channels by phosphatidylinositol 4,5-bisphosphate. Journal of Neuroscience, 25(7), 1674-1681.

Mezquita, B., Mezquita, P., Pau, M., Mezquita, J., \& Mezquita, C. (2014). Unlocking doors without keys: Activation of Src by truncated Cterminal intracellular receptor tyrosine kinases lacking tyrosine kinase activity. Cells, 3(1), 92-111.

Mickle, A. D., Shepherd, A. J., \& Mohapatra, D. P. (2015). Sensory TRP channels: the key transducers of nociception and pain. Progress in Molecular Biology and Translational Science, 131, 73-118.

Morgan, K., Sadofsky, L. R., Crow, C., \& Morice, A. H. (2014). Human TRPM8 and TRPA1 pain channels, including a gene variant with increased sensitivity to agonists (TRPA1 R797T), exhibit differential regulation by SRC-tyrosine kinase inhibitor. Bioscience Reports, 34(4), e00131. https://doi.org/10.1042/BSR20140061
Nagae, M., Hiraga, T., Wakabayashi, H., Wang, L., Iwata, K., \& Yoneda, T. (2006). Osteoclasts play a part in pain due to the inflammation adjacent to bone. Bone, 39(5), 1107-1115.

Nam, S., Kim, D., Cheng, J. Q., Zhang, S., Lee, J. H., Buettner, R., ... Jove, R. (2005). Action of the Src family kinase inhibitor, dasatinib (BMS354825), on human prostate cancer cells. Cancer Research, 65(20), 9185-9189.

Noyer, L., Grolez, G. P., Prevarskaya, N., Gkika, D., \& Lemonnier, L. (2018). TRPM8 and prostate: A cold case?". Pflügers Archiv-European Journal of Physiology, 470(10), 1419-1429.

Premkumar, L. S., Raisinghani, M., Pingle, S. C., Long, C., \& Pimentel, F. (2005). Downregulation of transient receptor potential melastatin 8 by protein kinase C-mediated dephosphorylation. Journal of Neuroscience, 25(49), 11322-11329.

Reid, G., Amuzescu, B., Zech, E., \& Flonta, M. L. (2001). A system for applying rapid warming or cooling stimuli to cells during patch clamp recording or ion imaging. Journal of Neuroscience Methods, 111(1), 1-8.

Tsavaler, L., Shapero, M. H., Morkowski, S., \& Laus, R. (2001). Trp-p8, a novel prostate-specific gene, is up-regulated in prostate cancer and other malignancies and shares high homology with transient receptor potential calcium channel proteins. Cancer Research, 61(9), 3760-3769.

Voets, T., Owsianik, G., Janssens, A., Talavera, K., \& Nilius, B. (2007). TRPM8 voltage sensor mutants reveal a mechanism for integrating thermal and chemical stimuli. Nature Chemical Biology, 3, 174.

Wegierski, T., Lewandrowski, U., Müller, B., Sickmann, A., \& Walz, G. (2009). Tyrosine phosphorylation modulates the activity of TRPV4 in response to defined stimuli. Journal of Biological Chemistry, 284(5), 2923-2933.

Xiao, X., Zhao, X. T., Xu, L. C., Yue, L. P., Liu, F. Y., Cai, J., ... Wan, Y. (2015). Shp-1 dephosphorylates TRPV1 in dorsal root ganglion neurons and alleviates CFA-induced inflammatory pain in rats. Pain, 156(4), 597-608.

Yin, Y., Wu, M., Zubcevic, L., Borschel, W. F., Lander, G. C., \& Lee, S. Y. (2018). Structure of the cold- and menthol-sensing ion channel TRPM8. Science, 359(6372), 237-241.

Yudin, Y., \& Rohacs, T. (2012). Regulation of TRPM8 channel activity. Molecular and Cellular Endocrinology, 353(1-2), 68-74.

Zakharian, E., Cao, C., \& Rohacs, T. (2010). Gating of transient receptor potential melastatin 8 (TRPM8) channels activated by cold and chemical agonists in planar lipid bilayers. Journal of Neuroscience, 30(37), 12526-12534.

Zakharian, E., Thyagarajan, B., French, R. J., Pavlov, E., \& Rohacs, T. (2009). Inorganic polyphosphate modulates TRPM8 channels. PLOS One, 4(4), e5404.

Zhang, W., Tong, Q., Conrad, K., Wozney, J., Cheung, J. Y., \& Miller, B. A. (2007). Regulation of TRP channel TRPM2 by the tyrosine phosphatase PTPL1. American Journal of Physiology-Cell Physiology, 292(5), C1746-C1758.

Zhang, X., Huang, J., \& McNaughton, P. A. (2005). NGF rapidly increases membrane expression of TRPV1 heat-gated ion channels. The EMBO Journal, 24(24), 4211-4223.

How to cite this article: Manolache A, Selescu T, Maier GL, et al. Regulation of TRPM8 channel activity by Src-mediated tyrosine phosphorylation. J Cell Physiol. 2019;1-12. https://doi.org/10.1002/jcp.29397 